\title{
sciendo
}

ISSN: $1231-4005$

e-ISSN: $2354-0133$

DOI: $10.2478 /$ kones-2019-0104

\section{APPLICATION OF SIMILARITY METHOD OF DISTANCE COURSES DESCRIBING THE ELEMENTS CONTENT IN TYPICAL CEMENT CONCRETE AFTER THERMAL CYCLES}

\author{
Malgorzata Linek \\ Kielce University of Technology \\ Faculty of Civil Engineering and Architecture \\ Department of Transportation Engineering \\ Tysiaclecia Państwa Polskiego Street 7, 25-314 Kielce, Poland \\ tel.: +48413424844 \\ e-mail:linekm@tu.kielce.pl
}

Piotr Nita

Air Force Institute of Technology

Ksiecia Boleslawa Street 6, 01-494 Warsaw, Poland

tel.: +48261851424

e-mail:piotr.nita@itwl.pl

\begin{abstract}
The work concerns the use of similarity analysis of distance course. Composition of concrete mixes was designed. The cement concrete composition includes cement, coarse aggregate, fine aggregate, water and admixtures. The laboratory analyses included concretes curing in standard conditions and concretes subject to thermal cycles representing the destructive influence of imposed loading. Laboratory tests assumed the fifty thermal test cycles. A single test cycle included process of alternate heating and cooling. Recurrent influence of temperature stimulated the impact of aircraft on airfield pavements. The assumed heating and cooling time corresponded to the time during which the aircraft effected the most frequently used airfield pavement within the area of Poland. Comparative SEM observations of concretes subject to thermal cycles were conducted. An increase in the width of microcracs has been observed. In case of crystallization, there is diversification within the area of cement matrix, contact area between cement matrix and aggregate grains and in case of porosity characteristics of both concretes. Similarity indexes between input and target sequence were defined. Diagrams presenting the similarity of the analysed concretes were prepared (after 28 days of curing and after thermal cycles). It was proved that the suggested method could be used to define the similarity of concrete intended for airfield pavements.
\end{abstract}

Keywords: cement concrete, airfield pavement, analysis of similarity, thermal cycles

\section{Purpose and scope of the research}

The publication presents the assessment of an opportunity to apply the analysis of similarity of distance courses with respect to cement concrete. The analysis included typical cement concrete intended for airfield pavements, in compliance with [4] requirements. The scope of works consisted:

- designing the composition of a concrete mix with the requirements of [4],

- preparation of concrete samples with the requirements of [5],

- curing of concrete with the requirements of [6],

- assessing influence of forced thermal loads on the hardened concrete [3].

The designed aggregate mixes of series BW complied with the requirements of [4]. The aggregate compositions of the designed mixes were considered as good grain size distribution of airfield pavements. 
Composition of aggregate included [1]:

- sand in the quantity of $390 \mathrm{~kg} / \mathrm{m}^{3}$,

- granite grit fraction $2 / 8 \mathrm{~mm}$ in the quantity of $510 \mathrm{~kg} / \mathrm{m}^{3}$,

- granite grit fraction $8 / 16 \mathrm{~mm}$ in the quantity of $430 \mathrm{~kg} / \mathrm{m}^{3}$,

- granite grit fraction $16 / 32 \mathrm{~mm}$ in the quantity of $442 \mathrm{~kg} / \mathrm{m}^{3}$.

Composition of concrete mixture included [1-3]:

- cement in the quantity of $370 \mathrm{~kg} / \mathrm{m}^{3}$,

- water in the quantity of $148 \mathrm{~kg} / \mathrm{m}^{3}$,

- air entraining agent $-1.74 \mathrm{~kg} / \mathrm{m}^{3}$,

- plasticizing admixture $-0.63 \mathrm{~kg} / \mathrm{m}^{3}$.

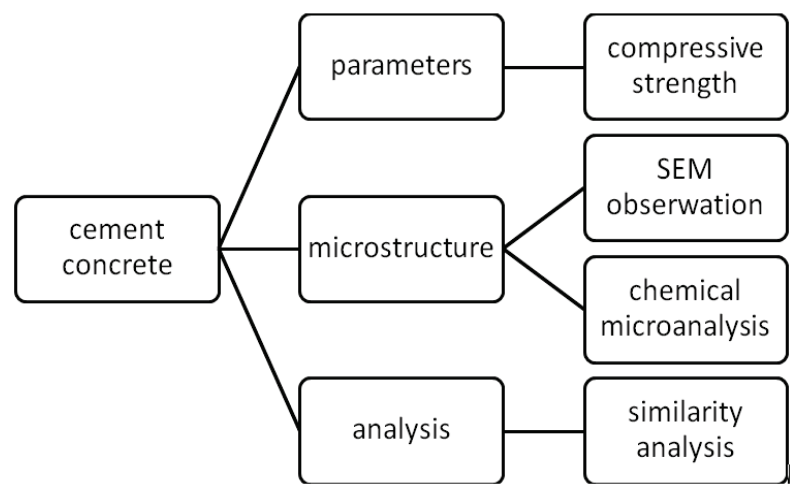

Fig. 1 Diagram of the research process

The obtained parameters of mixes and concrete after 28 days of curing (BW) and subject to 50 forced thermal loads $\left(\mathrm{WBW}_{50}\right)$ were presented in the Tab. 1.

Tab. 1. Parameters of mixes and concretes

\begin{tabular}{|l|c|c|c|c|c|}
\hline \multicolumn{2}{|c|}{ Parameters } & Unit & BW & \multicolumn{2}{c|}{ WBW $_{50}$} \\
\hline \multirow{2}{*}{ Concrete mixture } & \multicolumn{2}{|c|}{ Air content } & $\%$ & \multicolumn{2}{c|}{4.5} \\
\cline { 2 - 6 } & \multicolumn{2}{|c|}{ Class of consistency } & - & \multicolumn{2}{c|}{ S1 } \\
\hline \multirow{2}{*}{ Cement concrete } & \multirow{2}{*}{ Compressive strength } & $\bar{X}$ & $\mathrm{MPa}$ & 60.4 & 81.7 \\
\cline { 2 - 6 } & & $\sigma$ & $\mathrm{MPa}$ & 1.657 & 1.786 \\
\hline
\end{tabular}

Compression strength in case of hardened concrete was determined. The size of the test samples was $150 \times 300 \mathrm{~mm}$. Samples size and the loading method were consistent with the requirements of [7]. In the course of the test, maximum load value was determined. The concrete sample is capable to transfer the load before it is damaged. Concrete compressive strength $\left(f_{c}\right)$ was determined according to formula (1):

$$
f_{c}=\frac{F}{A_{c}},
$$

where:

$F$ - maximum load applied to the sample [N],

$A_{c}$ - cross-sectional area of the sample [mm].

Laboratory tests assumed the fifty thermal test cycles. A single test cycle included process of alternate heating and cooling - Tab. 2. Recurrent influence of temperature stimulated the impact of aircraft on airfield pavements. The assumed heating and cooling time corresponded to the time during which the aircraft effected the most frequently used airfield pavement within the area of Poland. Velocity of gas stream emitted during the test was $30 \mathrm{~m} / \mathrm{s}$. 
Tab. 2. Single test cycle

\begin{tabular}{|l|c|c|c|}
\hline Conditions & Heating & Cooling & Test cycle \\
\hline Time $[\mathrm{s}]$ & 60 & 900 & 960 \\
\hline Temperature $\left[{ }^{\circ} \mathrm{C}\right]$ & $250 \pm 2$ & $20 \pm 2$ & $250-20$ \\
\hline
\end{tabular}

Internal structure of concrete composite was also assessed. Scanning electron microscope was used for this purpose. Fresh fractures were performed taking concrete samples; the preparation surface subject to SEM observations was not less than $1.0 \mathrm{~cm}^{2}$. The extent of magnification was from $200 \times$ to $100000 \times$. Chemical microanalyses of selected sections in concrete composite were performed, as well. The results obtained during the first stage served as the basis for the analysis of similarity of distance courses of analysed concretes [3].

\section{Tests results and their analysis}

Accumulation of carbonates in the surface zone and numerous discontinuities were determination. Pursuant to observations of fracture of BW (Fig. 2) and $\mathrm{WBW}_{50}$ (Fig. 3) concrete series, it was proved that, internal structure changed. An increase in the width of microcracs has been observed. In case of crystallization, there is diversification within the area of cement matrix, contact area between cement matrix and aggregate grains and in case of porosity characteristics of both concretes.
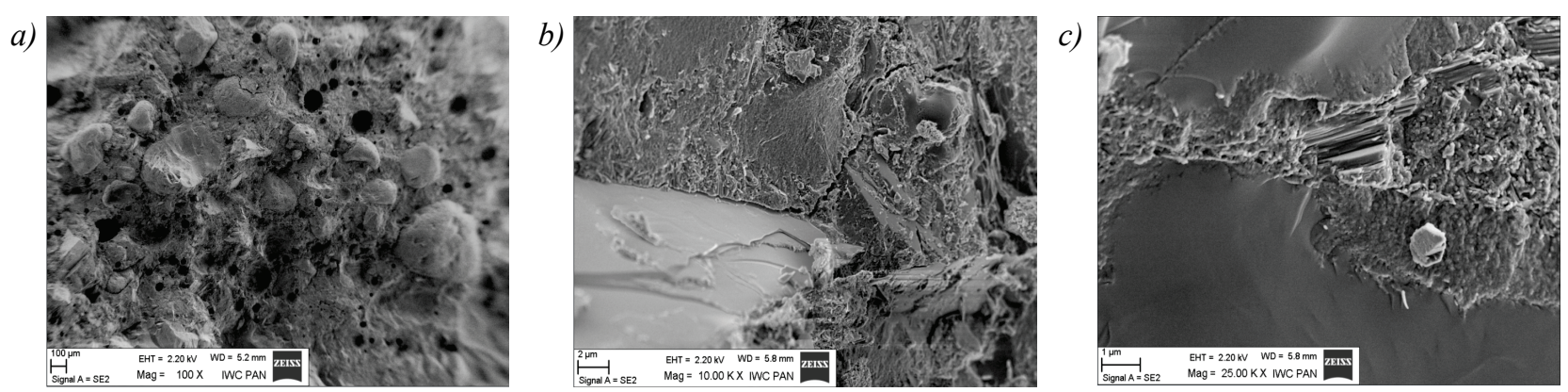

Fig. 2. Internal microstructure of BW concrete in selected sections: a) cement matrix, b) contact area between fine aggregate and cement matrix $x_{t}$ and c) contact area between granite aggregate and cement matrix
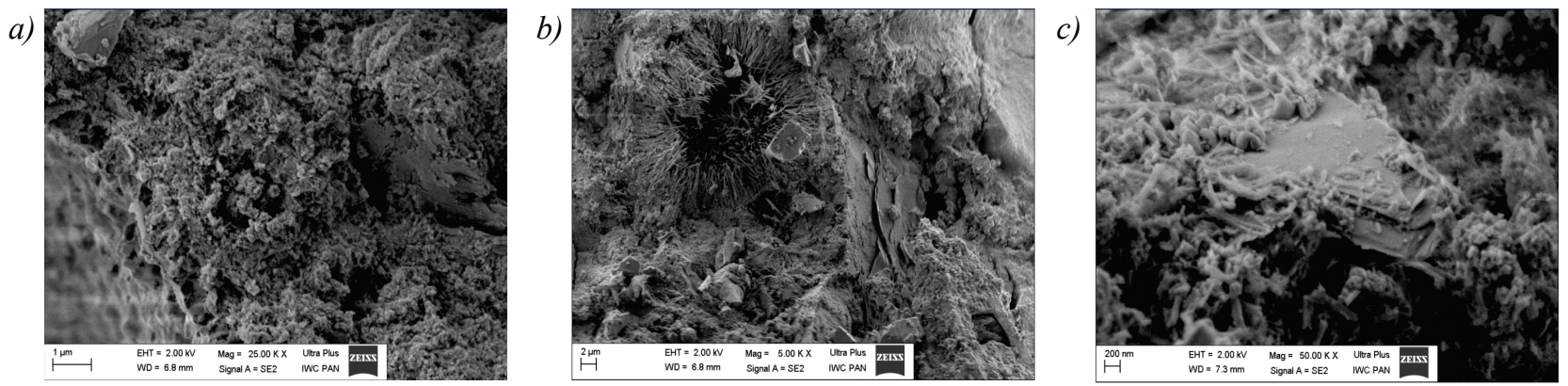

Fig. 3. Internal microstructure of $W B W_{50}$ concrete in selected sections: a) cement matrix, b)contact area between fine aggregate and cement matrix $t_{t}$ and c) contact area between granite aggregate and cement matrix

Data obtained as a result of chemical microanalysis (average values of 6 analyses) of concretes was subject to similarity analysis - Fig. 4 and 5. As an input sequence in similarity analysis, $\mathrm{WBW}_{50}$ characteristics values obtained as $\mathrm{w}$ result of microanalysis of $\mathrm{BW}$ concrete series were assumed. Basic input sequence characteristics were presented in Tab. 2, while Fig. 6 and 7 presents the original form of input and target sequence (accordingly distance courses of original input and target sequence and path leading to the smallest distance between the input and target sequences). 

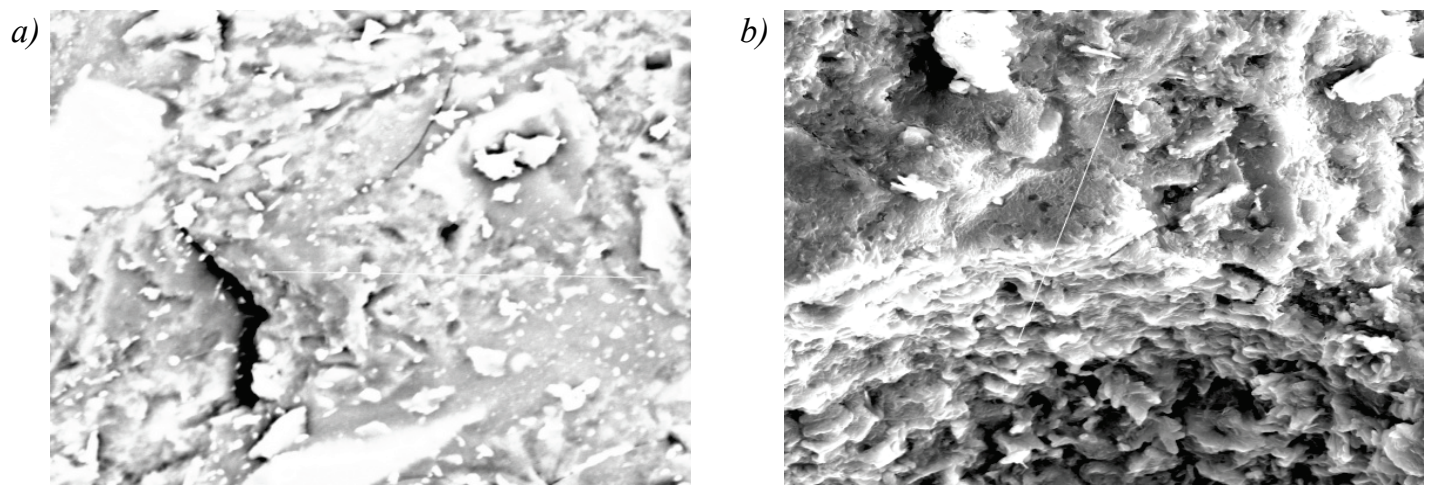

Fig. 4. Exemplary microanalysis of BW concrete: a) contact area between fine aggregate grains and cement matrix, b) cement matrix

a)

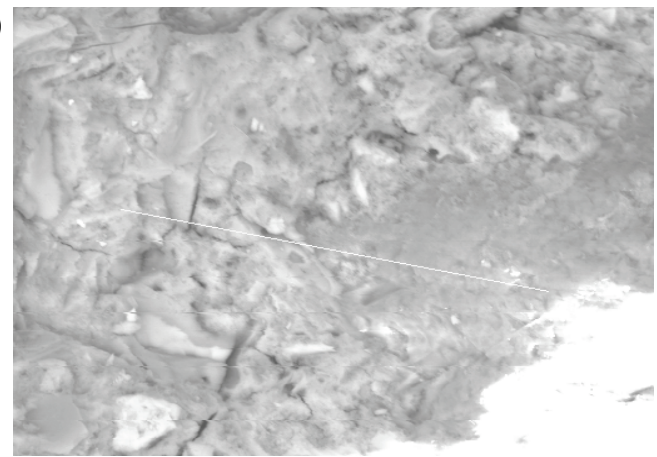

b)

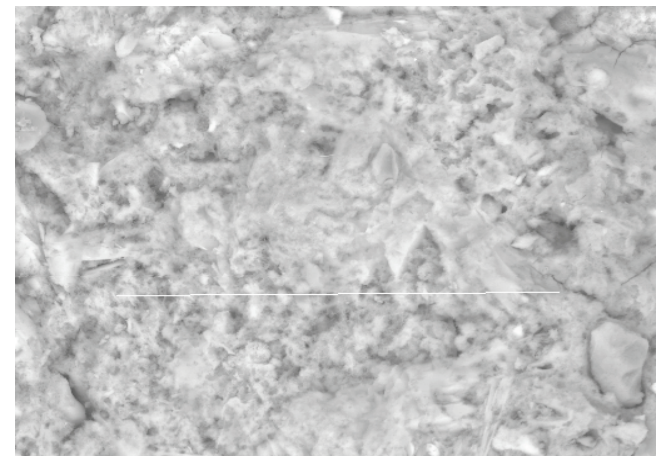

Fig. 5. Exemplary microanalysis of $W B W_{50}$ concrete: a) contact area between fine aggregate grains and cement matrix, b) cement matrix

Tab. 2. Input sequence characteristics in case of the selected element (oxygen) within cement matrix section

\begin{tabular}{|c|c|c|c|c|c|}
\hline Variable & A number of observations & Minimum & Maximum & Mean & Standard deviation \\
\hline $\mathrm{WBM}_{50}$ & 64 & 9.40 & 48.66 & 31.34 & 9.16 \\
\hline
\end{tabular}

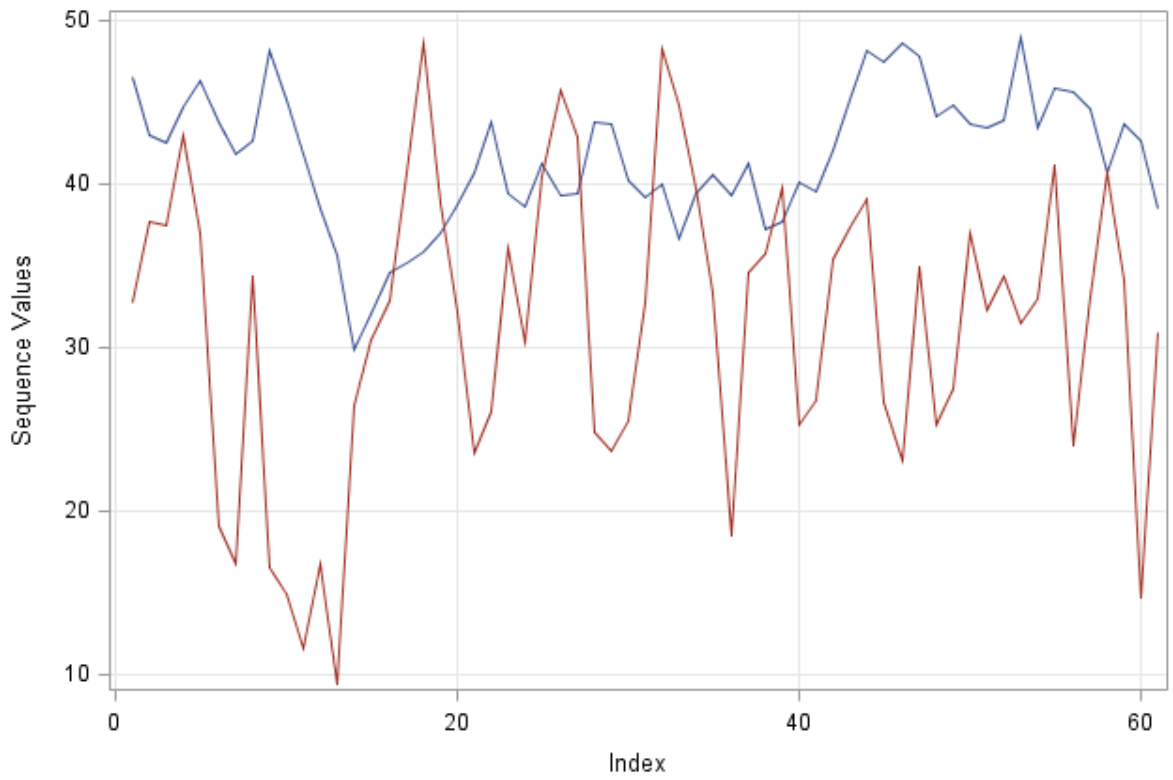

Fig. 6. Distance courses of original input sequence (red) and target sequence (blue)

In general case, the analysed courses were represented as $\left(x_{1}, x_{2}, \ldots, x_{n x}\right)$ for input sequence and $\left(y_{1}, y_{2}, \ldots, y_{n y}\right)$ for target sequence. The path was determined, which leads from the least average 
distance along the path. Fig. 7 presents the route of such path in case of the considered sequences. Statistics concerning the path present the amount of compression and expansion of target sequence with respect to input sequence.

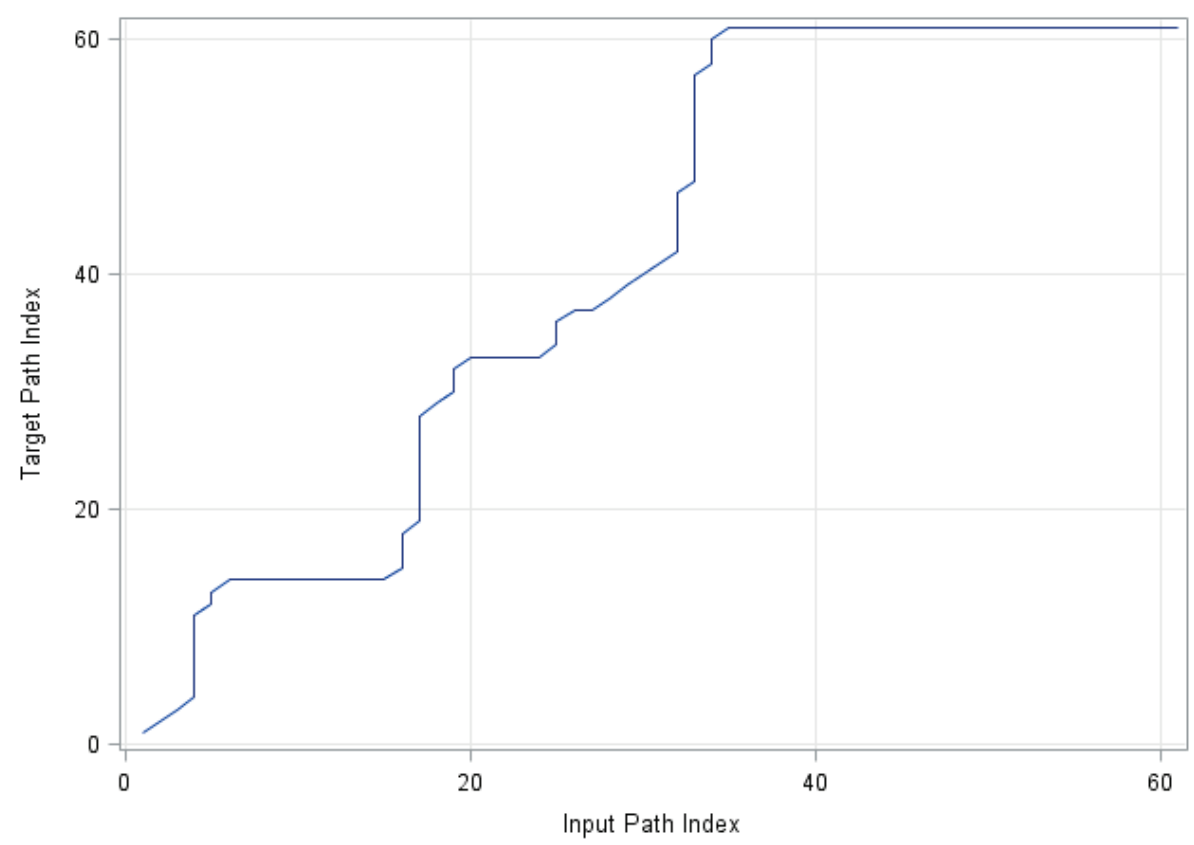

Fig. 7. Path leading to the smallest distance between the input and target sequences

Distances were determined (Fig. 8) between the values of input and target sequences along the optimal path. Path indexes are placed on the axis of abscissa. Bold horizontal line refers to the average distance; the two remaining horizontal lines refer to distances, which differ from the average one by one or two standard deviations. Fig. 9 presents distance histogram between input and target sequences along optimal path with the indicated Gauss's curve and nuclear density curve.

According to the conducted analysis, similarity index was obtained between the input and target sequences along the optimal path, which is 5.09495.

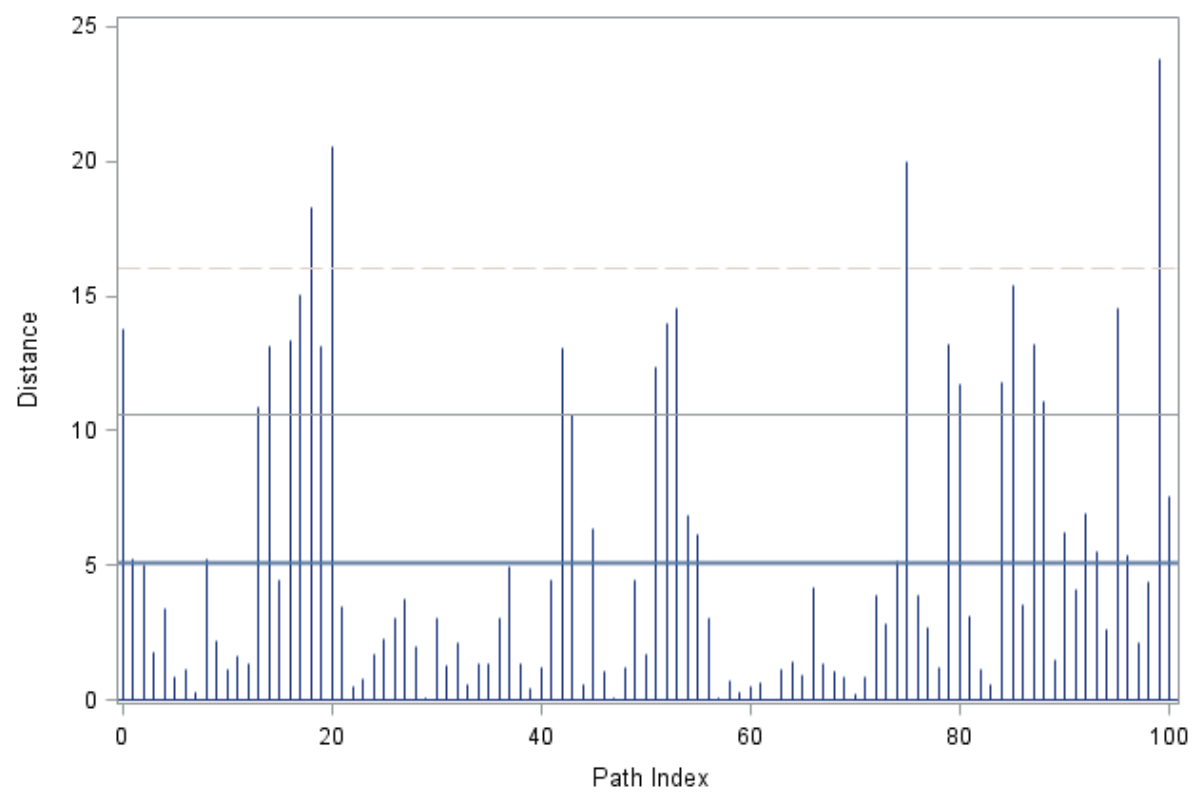

Fig. 8. Distance between the input and target sequences along optimal path 


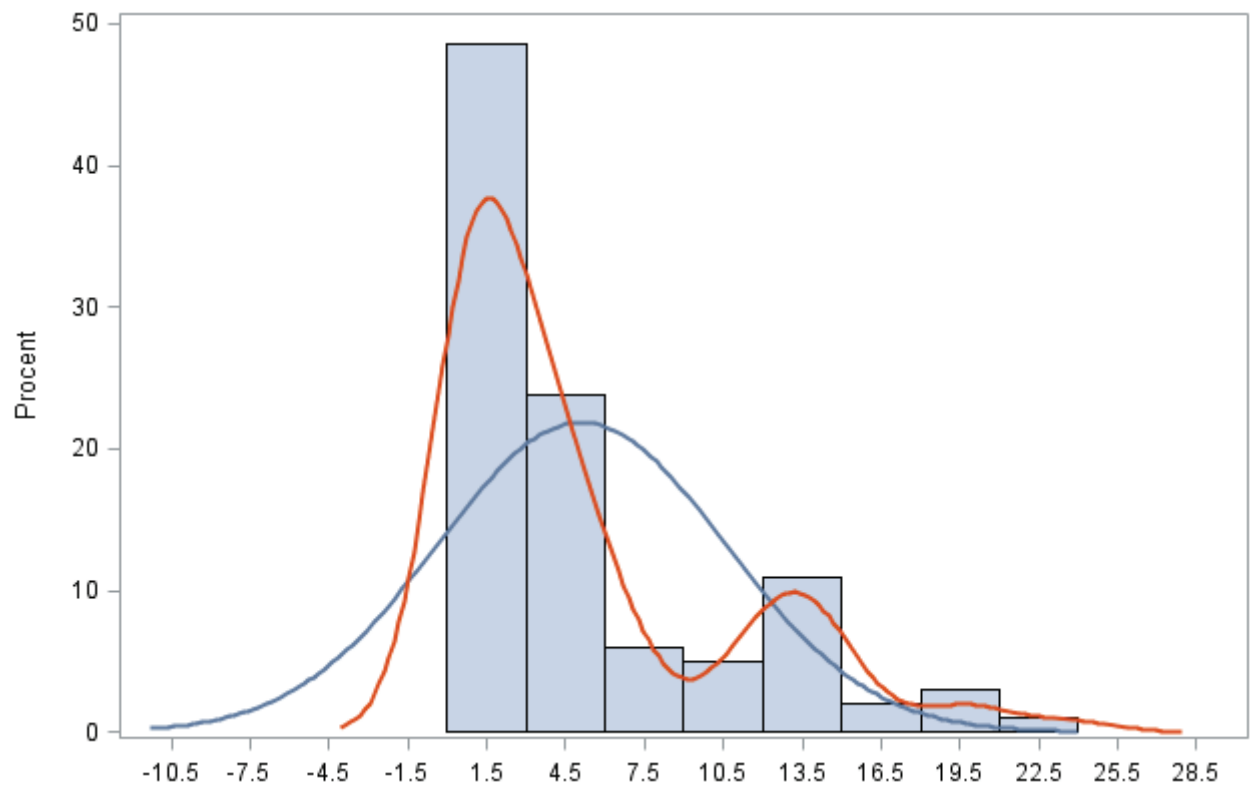

Fig. 9. Histogram of distance between input and target sequences along optimal path with indicated Gauss's curve (blue) and nuclear density curve (red)

Figure 10 presents the distance between values of input and target sequences along the optimal path. Path indexes are located on the axis of abscissa. Fig. 11 presents histogram of distance between standardized input and target sequences along optimal path with the indicated Gauss's curve and nuclear density curve.

The final effect of the conducted analysis was to define similarity index between input and target sequences along the optimal path, which is 0.40709 .

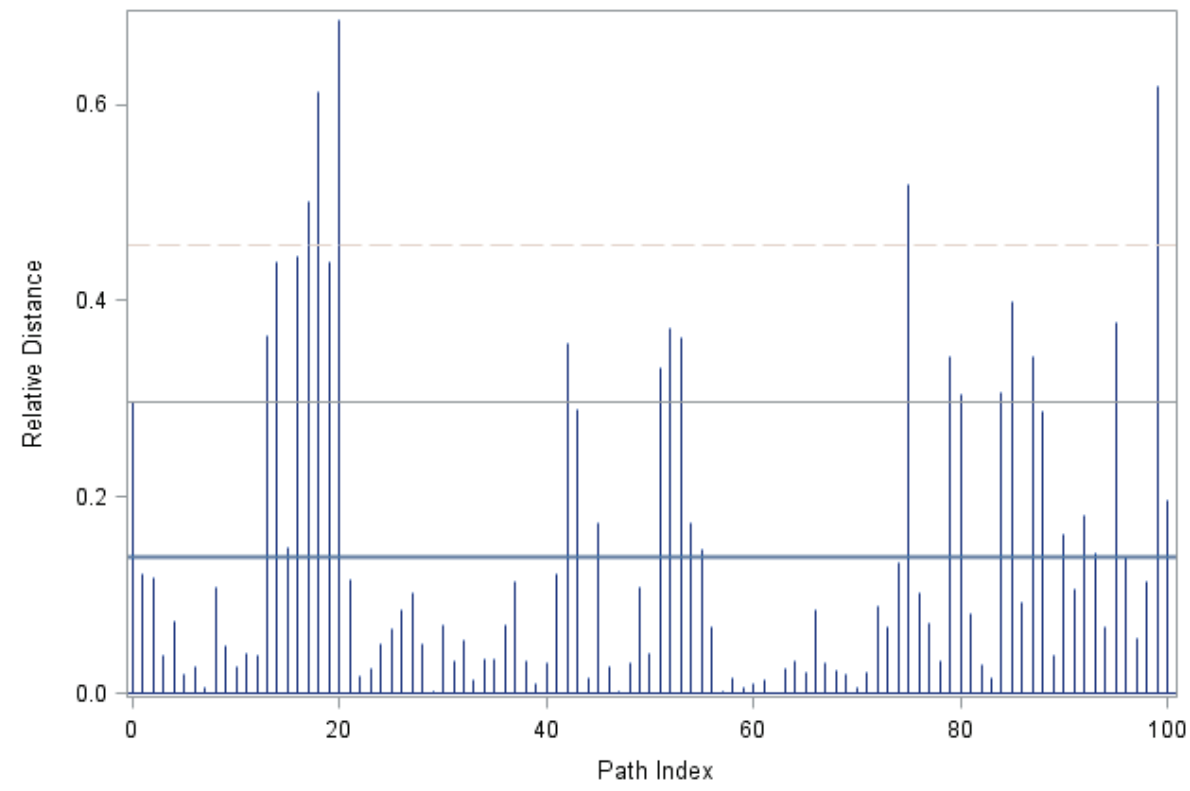

Fig. 10. Diagram of distance between standardized input sequence and standardized target sequence along optimal path

The scope of the conducted analyses included diversification in terms of content of chemical elements: carbon, oxygen, aluminum, silicon, sulphur, potassium, calcium, iron, sodium, magnesium. The analyses included cement matrix, contact area between cement matrix and granite grain, contact area between cement matrix and quartz grain, contact area between cement matrix and the air void. So far, range of chemical microanalysis with the use of formal similarity analysis 
of the obtained data has been conducted for concrete BW [1] and concrete BW after 200 cycles of frost resistance [2]. Similarity indexes included in Tab. 3 were obtained analogically, as described above. These indexes allow assessing independently the similarity of each concrete with respect to contents of individual elements in the considered areas.

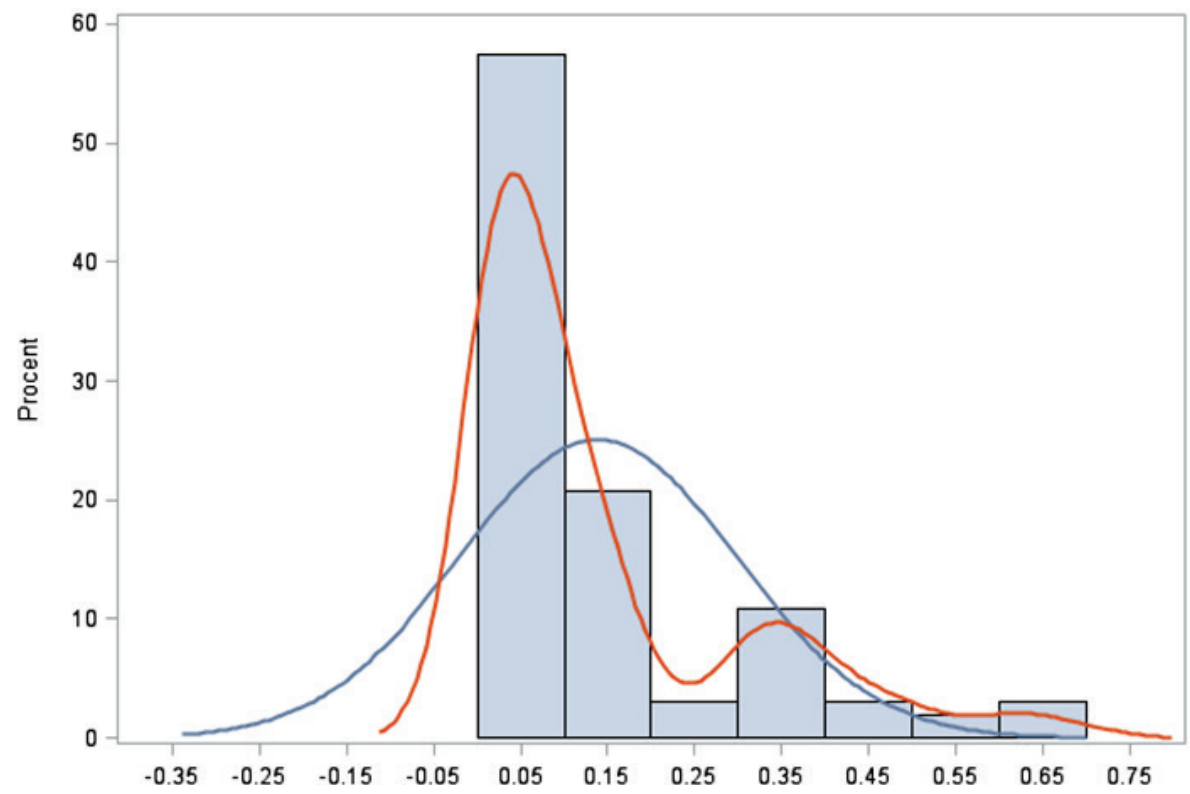

Fig. 11. Histogram of distance between standardized input sequence and standardized target sequence along optimal path with the indicated Gauss's curve (blue) and nuclear density curve (red)

Tab. 3. The list of similarity indexes $w_{p}$ for selected areas

\begin{tabular}{|c|c|c|c|c|c|c|c|c|c|}
\hline \multicolumn{1}{|c|}{ element } \\
\hline $\mathrm{C}$ & $\mathrm{O}$ & $\mathrm{Al}$ & $\mathrm{Si}$ & $\mathrm{S}$ & $\mathrm{K}$ & $\mathrm{Ca}$ & $\mathrm{Fe}$ & $\mathrm{Na}$ & $\mathrm{Mg}$ \\
\hline \multicolumn{8}{|c|}{ cement matrix } \\
\hline 0.4349 & 0.4071 & 0.3417 & 0.4149 & 0.7806 & 0.4313 & 0.4388 & 0.3042 & 0.8072 & 0.7311 \\
\hline \multicolumn{8}{|c|}{ cement matrix - air void } \\
\hline 0.3436 & 0.4104 & 0.4181 & 0.2975 & 0.3931 & 0.5213 & 0.5456 & 0.4066 & 0.6075 & 0.5605 \\
\hline \multicolumn{8}{|c|}{ cement matrix - quartz aggregate } \\
\hline 0.5203 & 0.3871 & 0.4614 & 0.2366 & 0.8331 & 0.4629 & 0.3813 & 0.3714 & 0.7389 & 0.7751 \\
\hline \multicolumn{8}{|c|}{ cement matrix - granite aggregate } \\
\hline 0.6989 & 0.3646 & 0.6655 & 0.7019 & 0.0000 & 0.6759 & 0.7854 & 0.7373 & 0.0000 & 0.0000 \\
\hline
\end{tabular}

According to the obtained similarity indexes, diagrams presenting ,proximity" of distance courses of the analysed concretes were prepared, with respect to reference concrete in terms of contents of elements in matrix and contact areas with quartz, and granite grains and air voids. The polygon method was used. The shape and size of the result polygons, in minor extent, depend on the order of attributes.

In order to create polygons, values of each attribute were arranged and then the length of radii indicating vertices of individual polygons was calculated. Values of the first attribute were presented on the radius of Ox axis direction. Values of the next attributes are located on the subsequent radii, counted from the first one counter-clockwise. Over the radius corresponding with the first attribute, there is the radius referred to the second attribute and under thereof - to the last attribute. Attributes are similarity indexes of distance courses of concrete and reference concrete for subsequent elements in the defined area. 
Based on the obtained distance courses (Tab. 4), it was proved that the influence of results standardization is a significant factor ( $a$ and $b$ ). Smaller polygon proves higher similarity of concrete to the reference concrete.

Tab. 4. The polygon method for data prior standardization (a) and data after standardization (b)

\begin{tabular}{|c|c|c|c|c|}
\hline & \multicolumn{4}{|c|}{ Selected analysis area } \\
\hline & Cement matrix & $\begin{array}{l}\text { Cement matrix - air } \\
\text { void }\end{array}$ & $\begin{array}{l}\text { Cement matrix - } \\
\text { quartz aggregate }\end{array}$ & $\begin{array}{l}\text { Cement matrix - } \\
\text { granite aggregate }\end{array}$ \\
\hline & a) & 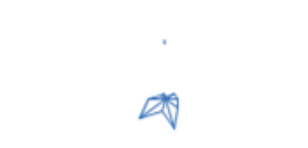 & $\Delta$ & 8 \\
\hline
\end{tabular}

Analysing the data before the standardization it was proved that the contact area between the air void and cement matrix, the contact area between the granite aggregate and cement matrix and the contact area between the quartz aggregate and cement matrix has the most similar distance courses to the reference concrete. The highest diversification was proved in case of cement matrix.

Analysing the data after the standardization it was proved that the most significant differences were found within the contact area between the cement matrix and quartz aggregate.

\section{Conclusions}

According to the conducted laboratory tests, the following conclusions have been reached:

1) The internal microstructure of WBW concrete after 50 thermal forced cycles with respect to the comparative concrete was changed.

2) The similarity index between input and target sequences along the optimal path was defined as 5.09495 without standardization and 0.40709 after standardization.

3) It was proved that the influence of results standardization is very important to determine a similarity of concretes.

4) According to the analysis of the obtained distance courses for the concrete $\mathrm{WBW}_{50}$ it was proved that the most significant differences occur within the contact area between the cement matrix and fine aggregate grains.

\section{References}

[1] Linek, M., Application of similarity method of distance courses describing the elements content in pavement quality concrete, Journal of KONES Powertrain and Transport, Vol. 24, No. 4, pp. 393-398, 2017.

[2] Linek, M., Nita, P., Application of similarity method of distance courses describing the elements content in typical cement concrete, Journal of KONES Powertrain and Transport, Vol. 25, No. 4, pp. 239-246, 2018.

[3] Linek, M., Surface concrete with improved parameters of physical and mechanical on the loads caused by forced temperature, PhD Thesis, Kielce 2013.

[4] NO 17-A204:2015, Airfield concrete pavements - Requirements and test methods for cement concrete pavements, Polish Standard.

[5] PN-EN 12390-1:2013, Testing hardened concrete - Part 1: Shape, dimensions and other requirements for specimens and moulds, Polish Standard.

[6] PN-EN 12390-2:2011, Testing hardened concrete - Part 2: Making and curing speciments for strength tests, Polish Standard.

[7] PN-EN 12390-3:2011, Testing hardened concrete - Part 3: Compressive strenth of test specimens, Polish Standard.

Manuscript received 26 August 2019; approved for printing 19 December 2019 